\title{
Normal-tension Glaucoma Management: A Survey of Glaucoma Sub-specialists in Korea
}

\author{
Young Soo Han, Ahnul Ha, Young Kook Kim, Jin Wook Jeoung, Ki Ho Park \\ Department of Ophthalmology, Seoul National University Hospital, Seoul National University College of Medicine, Seoul, Korea
}

Purpose: To investigate the current management patterns of glaucoma subspecialists with regard to normal-tension glaucoma (NTG) in Korea and to determine the effect of the two largest NTG trials on their clinical practice.

Methods: A questionnaire survey was sent to glaucoma subspecialist members of the Korean Glaucoma Society. The questionnaire concerned regular practice with respect to NTG and the extent to which it has been influenced by the Collaborative Normal-tension Glaucoma Study and the Low-pressure Glaucoma Treatment Study (LoGTS).

Results: A total of 134 glaucoma subspecialists completed the survey, with a response rate of $56 \%$. The survey reported that $88 \%$ and $78 \%$ of glaucoma subspecialists were familiar with the Collaborative Normal-tension Glaucoma Study and the LoGTS, respectively. With respect to mild or moderate NTG, most of the respondents (87\%-91\%) tended to treat their patients immediately without waiting for structural or functional progression. Among the respondents, 47 indicated that the LoGTS results-according to which, $20 \%$ of the respondents tended to use brimonidine more often-affected their management. The first-choice topical drugs for NTG were prostaglandin analogues (76\%), brimonidine (9\%), beta-blockers (8\%), and topical carbonic anhydrase inhibitor (6\%).

Conclusions: Regarding mild-to-moderate NTG, Korean glaucoma subspecialists tended to initiate treatment without waiting for further progression. The impact of the LoGTS on NTG management was not dominant in clinical practice in Korea. Prostaglandin analogs are the most frequently selected first-choice drugs for the management of NTG in Korea.

Key Words: Low tension glaucoma, Surveys and questionnaires, Therapy

Normal-tension glaucoma (NTG) is a form of primary open-angle glaucoma (POAG) that develops even within the normal range of intraocular pressure (IOP). It is characterized by glaucomatous optic neuropathy and the corresponding visual field defects. While NTG occurs in ap-

Received: May 8, 2020 Final revision: August 5, 2020

Accepted: August 6, 2020

Corresponding Author: Ki Ho Park, MD, PhD. Department of Ophthalmology, Seoul National University Hospital, Seoul National University College of Medicine, 101 Daehak-ro, Jongno-gu, Seoul 03080, Korea. Tel: 82-2-2072-2438, Fax: 82-2-741-3187, E-mail: kihopark@snu.ac.kr proximately $30 \%$ to $40 \%$ of patients with POAG in Western populations [1], it has been reported to be higher in East Asian populations. The Japanese Tajimi study [2] showed that NTG comprised $92 \%$ of POAG patients in its study population, and the Korean Namil study [3] reported a corresponding rate of $77 \%$. Due to the high prevalence of NTG in East Asia, an effective acute management strategy is of utmost importance in this region.

The Collaborative Normal-tension Glaucoma Study (CNTGS) [4] and the Low-pressure Glaucoma Treatment Study (LoGTS) [5,6] are two of the largest randomized dou- 
ble-blind controlled trials on NTG. The CTNGS provided important data on the natural history of NTG and the effects of IOP lowering in such cases. In the CNTGS, approximately $50 \%$ of the eyes with NTG remained stable when left untreated over the 5-year study period. According to this result, it was suggested that the initial NTG treatment should proceed cautiously. In the LoGTS, the brimonidine-treated NTG group relative to the timolol-treated group was less likely to show visual field progression over a 30-month follow-up period despite a similar IOP decrease. This finding suggests that brimonidine might have a possible additional neuroprotective effect that delays the visual-field progression rate.

Despite the high proportion of NTG among glaucoma cases in Korea, few studies have been conducted to date that accurately describe as to how NTG treatment proceeds in clinical practice. Kim et al. [7] reported, based on a retrospective medical chart review, that the most frequently used glaucoma drugs in Korean NTG management are prostaglandin, carbonic anhydrase inhibitor/beta-blocker fixed combination, and brimonidine/beta-blocker fixed combination. However, no study investigating the opinion of Korean glaucoma specialists regarding NTG management has been published. Thus, we investigated the usual practice of Korean glaucoma subspecialists regarding NTG management and the extent to which the CNTGS and LoGTS have influenced their treatment of patients.

\section{Materials and Methods}

\section{Ethics statement}

This study was approved by the institutional review board of Seoul National University Hospital (1911-181-1083) and conducted in accordance with the Declaration of Helsinki. All of the participants provided their written informed consent.

\section{Survey participants}

A questionnaire was sent by email to the members of the Korean Glaucoma Society (KGS). The eligibility requirements for KGS membership are as follows: (1) at least 2 years of active practice in a glaucoma clinic, including 1 year of glaucoma fellowship-training, and (2) authorship of at least two published papers on glaucoma.

\section{Survey methods}

A Google questionnaire form was used to collect the survey responses. The survey was designed such that respondents were able to complete the survey only once. The questions and answers referred to published papers [8], all of which were written in Korean. The English-Korean translation of the questionnaire was certified by a notary public office (Bubheung Law and Notary Office Inc., Seoul, Korea) authorized by the Minister of Justice, Korea. The answers to the questions regarding the frequency of practice were given on a five-point scale from always to never.

\section{Survey questionnaire}

The questionnaire consisted of questions on regular clinical practice in the management of NTG and the extent to which their practice has been influenced by the two largest clinical trials on NTG (i.e., CNTGS and LoGTS).

Questions 1 and 2 were queries on whether a respondent was familiar with the CNTGS and the LoGTS, respectively. Questions 3 and 4 were associated with the determination of when to start treatment for mild-to-moderate NTG, each being the inverse of the other, thus allowing for an internal check of the responses. Questions 5 and 6 asked about the prescription preference between brimonidine and beta-blocker, according to the results of the LoGTS. Question 7 inquired whether the results of the LoGTS affected the respondent when deciding on the management of NTG patients. Question 8 asked about the respondents' firstchoice topical drug for patients requiring drop-therapy for NTG. Complete details of the questionnaire are shown in Table 1 [8].

\section{Results}

\section{Survey respondents}

We sent emails to a total of 238 glaucoma subspecialists, and 134 of them completed the survey.

The survey response rate was 56.3\% (134 / 238). Questions 3 and 4, which were the inverse of each other, showed $90.2 \%$ matching results. 
Table 1. Questions and overall results

\begin{tabular}{|c|c|c|}
\hline Question & Permitted response & Response \\
\hline 1. Are you familiar with the CNTGS? & $\begin{array}{l}\text { Yes } \\
\text { No }\end{array}$ & $\begin{array}{r}118(88.1) \\
16(11.9)\end{array}$ \\
\hline 2. Are you familiar with the LoGTS? & $\begin{array}{l}\text { Yes } \\
\text { No }\end{array}$ & $\begin{array}{r}104(77.6) \\
30(22.4)\end{array}$ \\
\hline $\begin{array}{l}\text { 3. I follow-up NTG patients with mild or moderate glaucomatous change until they } \\
\text { have progressive change in the visual field and/or optic disc before initiating } \\
\text { treatment. }\end{array}$ & $\begin{array}{l}\text { Always } \\
\text { Usually } \\
\text { Sometimes } \\
\text { Rarely } \\
\text { Never } \\
\text { Usually/always } \\
\text { Never/rarely/sometimes }\end{array}$ & $\begin{aligned} 1 & (0.7) \\
11 & (8.2) \\
47 & (35.1) \\
68 & (50.7) \\
7 & (5.2) \\
12 & (9.0) \\
122 & (91.0)\end{aligned}$ \\
\hline $\begin{array}{l}\text { 4. On diagnosis of NTG with mild or moderate glaucomatous field change, I } \\
\text { aim to reduce the IOP at the time of diagnosis, without waiting for visual field } \\
\text { progression. }\end{array}$ & $\begin{array}{l}\text { Always } \\
\text { Usually } \\
\text { Sometimes } \\
\text { Rarely } \\
\text { Never } \\
\text { Usually/always } \\
\text { Never/rarely/sometimes }\end{array}$ & $\begin{aligned} & 27(20.1) \\
& 90(67.2) \\
& 13(9.7) \\
& 4(3.0) \\
& 0(0) \\
& 117(87.3) \\
& 17(12.7)\end{aligned}$ \\
\hline $\begin{array}{l}\text { 5. As suggested by the LoGTS results, with respect to brimonidine, I tend to use } \\
\text { brimonidine more often in patients with NTG. }\end{array}$ & $\begin{array}{l}\text { Always } \\
\text { Usually } \\
\text { Sometimes } \\
\text { Rarely } \\
\text { Never } \\
\text { Usually/always } \\
\text { Never/rarely/sometimes }\end{array}$ & $\begin{array}{c}2(1.5) \\
24(18.3) \\
45(34.4) \\
58(44.3) \\
2(1.5) \\
26(19.8) \\
105(80.2)\end{array}$ \\
\hline 6. I avoid using topical beta-blockers in patients with NTG. & $\begin{array}{l}\text { Always } \\
\text { Usually } \\
\text { Sometimes } \\
\text { Rarely } \\
\text { Never } \\
\text { Usually/always } \\
\text { Never/rarely/sometimes }\end{array}$ & $\begin{array}{c}2(1.5) \\
20(15.2) \\
43(32.6) \\
64(48.5) \\
3(2.3) \\
22(16.7) \\
110(83.3)\end{array}$ \\
\hline 7. Has the LoGTS study affected your management of patients with NTG? & $\begin{array}{l}\text { Yes } \\
\text { No }\end{array}$ & $\begin{array}{l}63(47.4) \\
70(52.6)\end{array}$ \\
\hline $\begin{array}{l}\text { 8. What is your first-choice topical drug when patients require drop-therapy for } \\
\text { NTG? }\end{array}$ & $\begin{array}{l}\text { Prostaglandin analogue } \\
\text { or prostamide } \\
\text { Beta-blocker } \\
\text { Topical carbonic } \\
\text { anhydrase inhibitor } \\
\text { Brimonidine } \\
\text { Cholinergic }\end{array}$ & $\begin{array}{r}100(75.8) \\
11(8.3) \\
8(6.1) \\
12(9.1) \\
1(0.8)\end{array}$ \\
\hline
\end{tabular}

Values are presented as number (\%); This table was adopted from Symes RJ et al. Can J Ophthalmol 2017;52:361-5 [8].

CNTGS = Collaborative Normal-Tension Glaucoma Study; LoGTS = Low-pressure Glaucoma Treatment Study; NTG = normal-tension glaucoma; IOP = intraocular pressure.

\section{Awareness of two clinical trials}

Most of the respondents answered that they were familiar with the CTNGS and the LoGTS (88.1\% and 77.6\%, respectively; questions 1 and 2).

\section{Initiation of NTG treatment}

Questions 3 and 4 concerned the starting point of the treatment for mild-to-moderate NTG. A binary analysis of the responses (always/usually vs. sometimes/rarely/never) showed $9.0 \%$ vs. $91.0 \%$ for question 3 and $87.3 \%$ vs. $12.7 \%$ for question 4 , meaning that $87 \%$ to $91 \%$ of the respon- 
dents tended to treat without waiting for further NTG deterioration.

\section{Impact of LoGTS on NTG management}

Of all the respondents, $47.4 \%$ answered that the LoGTS had influenced their clinical treatment (question 7). Questions 5 and 6 were related to the results of the LoGTS and the preferences of brimonidine or beta-blocker, respectively. To this end, the results of the binary analysis of the responses (always/usually vs. sometimes/rarely/never) were $19.8 \%$ vs. $80.2 \%$ and $16.7 \%$ vs. $83.3 \%$ for questions 5 and 6 , respectively, which implies that $80 \%$ to $83 \%$ of the respondents did not particularly prefer brimonidine over beta-blockers or avoid beta-blockers.

\section{First-choice topical drug for NTG}

The respondents stated that prostaglandin analogues (75.8\%), brimonidine (9.1\%), beta-blocker $(8.3 \%)$, and topical carbonic anhydrase inhibitor (6.1\%) were their firstchoice topical drugs for NTG treatment (question 8).

\section{Discussion}

In East Asian populations, the majority of patients (7792\%) diagnosed with POAG have IOP under $21 \mathrm{mmHg}$; thus, it would be particularly important to know the real-world practice for NTG management in these regions.

As we have endeavored to include as many KGS members as possible in the survey, we believe that the results may effectively represent the current NTG practice in Korea. Additionally, the response rate of our survey (56.3\%) was higher than the previously reported mean response rate $(35.0 \%)$ [9] for web-based surveys; thus, our survey seems to have been successful in terms of the response rate.

The CNTGS suggested two implications: (1) NTG patients benefit from IOP lowering, and (2) some portion of NTG patients (59\%) show disease stability without treatment over as many as 5 years of follow-up. Therefore, some ophthalmologists suggest that the mode of initial NTG treatment should be carefully selected. However, $87 \%$ to $91 \%$ of Korean glaucoma subspecialists do not delay the NTG treatment until they confirm a further pro- gressive change. The progression rate,s and thus, times to progression have been known to vary considerably among high-tension glaucoma, NTG, and pseudoexfoliation glaucoma [10]. The progression rate among cases of untreated NTG is also highly variable, with some cases showing progression within a few months [11]. A Japanese study group recently reported that the probability of NTG patients progressing to unilateral blindness was $9.9 \%$ at 20 years [12], which suggests that the NTG prognosis would be more severe than expected from the CNTGS. Additionally, individual factors that increase the risk of progression in NTG patients, such as optic disc hemorrhage [4,13], migraine [4], female [4], or IOP fluctuation [14,15], can affect the decision of Korean glaucoma subspecialists on whether to start treatment in the real-world clinical setting.

Symes and Mikelberg [8] reported contemporary NTG-management patterns among North American (American and Canadian) glaucoma subspecialists, whose data was compared with our present findings on Korean glaucoma subspecialists (Table 2) [8]. As shown, the North American glaucoma subspecialist (98.5\%) were more familiar with the CTNGS than the Koreans $(88.1 \%, p=$ 0.001). However, awareness of the LoGTS did not differ between the two groups. The Korean group $(91.0 \%$ and $87.3 \%$ ) showed a greater tendency to select immediate treatment than did the North American group $(72.0 \%$ and 67.4\%) (questions 3 and 4, $p<0.001$ ). The North American group (34.0\%) tended to use brimonidine more often in patients with NTG than did the Korean group (19.8\%) (question 5, $p=0.005)$. Also, the North American group (34.1\%) tended to avoid using topical beta-blockers more often than did the Korean group (16.7\%) (question 6, $p<0.001$ ). For question 7, the responses of the two groups with regard to the impact of the LoGTS did not significantly differ ( $p$ $=0.67)$. As for question 8 , the first-choice drug for NTG was significantly different between the two groups $(p<$ 0.001): the North American group chose prostaglandin analogues $(91.3 \%)$, followed by brimonidine $(8.0 \%)$, and they did not select beta-blockers $(0 \%)$, whereas the Korean group selected prostaglandin analogues $(75.8 \%)$, brimonidine $(9.1 \%)$, beta-blockers $(8.3 \%)$, and topical carbonic anhydrase inhibitor (6.1\%).

The Korean glaucoma subspecialists, as compared with the North American group, tended to start treatment earlier without waiting for further progression in mild-to-moderate NTG. According to previous studies, the proportion 
Table 2. Results of the Korean glaucoma subspecialists and North American glaucoma subspecialists

\begin{tabular}{|c|c|c|c|}
\hline Question & $\begin{array}{l}\text { Korean glaucoma subspecialist } \\
\qquad(\mathrm{n}=134)\end{array}$ & $\begin{array}{l}\text { North American glaucoma } \\
\text { subspecialist }(\mathrm{n}=265)\end{array}$ & $\begin{array}{c}\chi^{2} \text { or Fisher's exact } \\
\text { test / } p \text {-value }\end{array}$ \\
\hline 1. Are you familiar with the CNTGS? & Yes $118(88.1)$ & Yes $260(98.5)$ & $\begin{array}{l}\chi^{2} 16.081 \\
p<0.001^{*}\end{array}$ \\
\hline 2. Are you familiar with the LoGTS? & Yes $104(77.6)$ & Yes 206 (77.9) & $\begin{array}{l}\chi^{2} 0.004 \\
p=0.9445\end{array}$ \\
\hline $\begin{array}{l}\text { 3. I follow-up NTG patients with mild/ } \\
\text { moderate glaucomatous change } \\
\text { until they have progressive change } \\
\text { in the visual field and/or optic disc } \\
\text { before initiating treatment. }\end{array}$ & $\begin{array}{l}\text { Usually/always } 12(9.0) \text { vs. } \\
\text { never/rarely/sometimes } 122(91.0)\end{array}$ & $\begin{array}{l}\text { Usually/always } 74(28.0) \text { vs. } \\
\text { never/rarely/sometimes } 191(72.0)\end{array}$ & $\begin{array}{l}\chi^{2} 17.83 \\
p<0.001^{*}\end{array}$ \\
\hline $\begin{array}{l}\text { 4. On diagnosis of NTG with mild } \\
\text { or moderate glaucomatous field } \\
\text { change, I aim to reduce the IOP } \\
\text { at the time of diagnosis without } \\
\text { waiting for visual field progression. }\end{array}$ & $\begin{array}{l}\text { Usually/always } 117 \text { (87.3) vs. } \\
\text { never/rarely/sometimes } 17 \text { (12.7) }\end{array}$ & $\begin{array}{l}\text { Usually/always } 179(67.4) \text { vs. } \\
\text { never/rarely/sometimes } 86(32.6)\end{array}$ & $\begin{array}{l}\chi^{2} 17.14 \\
p<0.001^{*}\end{array}$ \\
\hline $\begin{array}{l}\text { 5. As suggested by the LoGTS results, } \\
\text { with respect to brimonidine, I tend } \\
\text { to use brimonidine more often in } \\
\text { patients with NTG. }\end{array}$ & $\begin{array}{l}\text { Usually/always } 26 \text { (19.8) vs. } \\
\text { never/rarely/sometimes } 105 \text { (80.2) }\end{array}$ & $\begin{array}{l}\text { Usually/always } 90(34.0) \text { vs. } \\
\text { never/rarely/sometimes } 175(66.0)\end{array}$ & $\begin{array}{l}\chi^{2} 7.76 \\
p=0.005^{*}\end{array}$ \\
\hline $\begin{array}{l}\text { 6. I avoid using topical beta-blockers } \\
\text { in patients with NTG. }\end{array}$ & $\begin{array}{l}\text { Usually/always } 22 \text { (16.7) vs. } \\
\text { never/rarely/ sometimes } 110(83.3)\end{array}$ & $\begin{array}{l}\text { Usually/always } 90(34.1) \text { vs. } \\
\text { never/rarely/sometimes } 175 \text { (65.9) }\end{array}$ & $\begin{array}{l}\chi^{2} 12.17 \\
p<0.001^{*}\end{array}$ \\
\hline $\begin{array}{l}\text { 7. Has the LoGTS study affected your } \\
\text { management of patients with NTG? }\end{array}$ & Yes 63 (47.4) & Yes $133(50.2)$ & $\begin{array}{l}\chi^{2} 0.18 \\
p=0.67\end{array}$ \\
\hline $\begin{array}{l}\text { 8. Brimonidine as first-choice topical } \\
\text { drug in NTG }\end{array}$ & $12(9.1)$ & $21(8.0)$ & $\begin{array}{l}\text { Fisher's exact test } \\
p<0.001^{*}\end{array}$ \\
\hline $\begin{array}{l}\text { Prostaglandin analogue as first- } \\
\text { choice drug in NTG }\end{array}$ & $100(75.8)$ & $242(91.3)$ & \\
\hline $\begin{array}{l}\text { Beta-blocker as first-choice drug in } \\
\text { NTG }\end{array}$ & $11(8.3)$ & $0(0)$ & \\
\hline
\end{tabular}

The $\chi^{2}$ test and Fisher's exact test were used to compare the groups; Values are presented as number (\%); This table was adopted from Symes RJ et al. Can J Ophthalmol 2017;52:361-5 [8].

CNTGS = Collaborative Normal-Tension Glaucoma Study; LoGTS = Low-pressure Glaucoma Treatment Study; NTG = normal-tension glaucoma; IOP = intraocular pressure.

*Statistically significant.

of NTG among glaucoma patients was 77\% [3] in Korea and $30 \%$ to $40 \%$ [1] in Western countries. This difference in NTG incidence between East Asian and Western people may have influenced the NTG treatment pattern in Korea. In terms of the LoGTS, both groups were well-aware of the trial, but the Korean group, relative to the North American group, tended to use less brimonidine and more beta-blockers. Brimonidine has the effect of reducing IOP in glaucoma regardless of race, whether Asian [16,17] or Western [18]; however, there have been no reports on ethnic differences in IOP drop. Due to the high drop-out rate (36.4\%) in the brimonidine group, Korean glaucoma specialists seem to have relatively less confidence in LoGTS results [6]. Another possible reason why Korean glaucoma specialists prefer brimonidine less than Western specialists is the seemingly higher frequency of occurrence of brimonidine allergy in Asians. Allergic reactions to brimonidine have been reported in $7.4 \%$ to $25.7 \%$ of the Western participants [19,20], and in $22.02 \%$ of Korean patients [21]. Moreover, as it has been reported that brimonidine metabolism is slower and its concentration is higher in highly pigmented eyes compared with relatively non-pigmented eyes $[22,23]$, there is a possibility that Koreans with dark brown irises might have increased susceptibility to allergies. These ethnic differences in NTG management should be investigated further by detailed surveying.

In our results, the overall response rate was $56.3 \%$, and thus, this study cannot be considered to completely repre- 
sent the views of Korean glaucoma subspecialists for NTG management. Nonetheless, our response rate was higher than the published mean response rate for emailed questionnaire surveys of physician specialists (35.0\%) [9] or those of North American glaucoma subspecialists (21\%$23 \%$ ). In addition, our survey was limited to two of the largest NTG clinical trials. Ideally, it would also have been interesting to ask the participants about other factors related to NTG management, such as nocturnal hypertension, diastolic blood pressure [24], or neuroprotective agents (e.g., Gingko biloba [25]). However, to maximize the questionnaire completion rate, it was necessary to keep it relatively short.

In conclusion, Korean glaucoma subspecialists tended to treat patients with mild-to-moderate NTG without waiting for disease progression. A minority of Korean glaucoma subspecialists have been influenced by the LoGTS results. Prostaglandin analogs are the most selected first-choice drug for the management of NTG.

\section{Conflict of Interest}

No potential conflict of interest relevant to this article was reported.

\section{References}

1. Mitchell P, Smith W, Attebo K, Healey PR. Prevalence of open-angle glaucoma in Australia. The Blue Mountains Eye Study. Ophthalmology 1996;103:1661-9.

2. Iwase A, Suzuki Y, Araie M, et al. The prevalence of primary open-angle glaucoma in Japanese: the Tajimi Study. Ophthalmology 2004;111:1641-8.

3. Kim CS, Seong GJ, Lee NH, et al. Prevalence of primary open-angle glaucoma in central South Korea the Namil study. Ophthalmology 2011;118:1024-30.

4. Anderson DR; Normal Tension Glaucoma Study. Collaborative normal tension glaucoma study. Curr Opin Ophthalmol 2003;14:86-90.

5. De Moraes CG, Liebmann JM, Greenfield DS, et al. Risk factors for visual field progression in the low-pressure glaucoma treatment study. Am J Ophthalmol 2012;154:70211.

6. Krupin T, Liebmann JM, Greenfield DS, et al. A random- ized trial of brimonidine versus timolol in preserving visual function: results from the Low-Pressure Glaucoma Treatment Study. Am J Ophthalmol 2011;151:671-81.

7. Kim CY, Park KH, Ahn J, et al. Treatment patterns and medication adherence of patients with glaucoma in South Korea. Br J Ophthalmol 2017;101:801-7.

8. Symes RJ, Mikelberg FS. Normal tension glaucoma management: a survey of contemporary practice. Can J Ophthalmol 2017;52:361-5.

9. Cunningham CT, Quan H, Hemmelgarn B, et al. Exploring physician specialist response rates to web-based surveys. BMC Med Res Methodol 2015;15:32.

10. Heijl A, Bengtsson B, Hyman L, et al. Natural history of open-angle glaucoma. Ophthalmology 2009;116:2271-6.

11. Anderson DR, Drance SM, Schulzer M; Collaborative Normal-Tension Glaucoma Study Group. Natural history of normal-tension glaucoma. Ophthalmology 2001;108:247-53.

12. Sawada A, Rivera JA, Takagi D, et al. Progression to legal blindness in patients with normal tension glaucoma: hospital-based study. Invest Ophthalmol Vis Sci 2015;56:3635-41.

13. Baek SU, Ha A, Kim DW, et al. Risk factors for disease progression in low-teens normal-tension glaucoma. $\mathrm{Br} J$ Ophthalmol 2020;104:81-6.

14. Bengtsson B, Leske MC, Hyman L, et al. Fluctuation of intraocular pressure and glaucoma progression in the early manifest glaucoma trial. Ophthalmology 2007;114:205-9.

15. Caprioli J, Coleman AL. Intraocular pressure fluctuation a risk factor for visual field progression at low intraocular pressures in the advanced glaucoma intervention study. Ophthalmology 2008;115:1123-9.

16. Liu CJ, Ko YC, Cheng CY, et al. Changes in intraocular pressure and ocular perfusion pressure after latanoprost $0.005 \%$ or brimonidine tartrate $0.2 \%$ in normal-tension glaucoma patients. Ophthalmology 2002;109:2241-7.

17. Tsumura T, Yoshikawa K, Kimura T, et al. The efficacy and safety of add-on $0.1 \%$ brimonidine tartrate preserved with sodium chlorite in on-treatment Japanese normal-tension glaucoma patients. Clin Ophthalmol 2014;8:1681-7.

18. Katz LJ. Brimonidine tartrate $0.2 \%$ twice daily vs timolol $0.5 \%$ twice daily: 1 -year results in glaucoma patients. Brimonidine Study Group. Am J Ophthalmol 1999;127:20-6.

19. Blondeau P, Rousseau JA. Allergic reactions to brimonidine in patients treated for glaucoma. Can J Ophthalmol 2002;37:21-6.

20. Schuman JS. Clinical experience with brimonidine $0.2 \%$ and timolol $0.5 \%$ in glaucoma and ocular hypertension. 
Surv Ophthalmol 1996;41 Suppl 1:S27-37.

21. Park EJ, Chun YS. Comparison of allergy prevalence between brimonidine/timolol fixed combination and $0.15 \%$ brimonidine in glaucoma patients. $J$ Korean Ophthalmol Soc 2018;59:451-8.

22. Acheampong AA, Shackleton M, Tang-Liu DD. Comparative ocular pharmacokinetics of brimonidine after a single dose application to the eyes of albino and pigmented rabbits. Drug Metab Dispos 1995;23:708-12.

23. Patil PM, Jacobowitz D. Unequal accumulation of adrener- gic drugs by pigmented and nonpigmented iris. Am J Ophthalmol 1974;78:470-7.

24. Kwon J, Jo YH, Jeong D, et al. Baseline systolic versus diastolic blood pressure dip and subsequent visual field progression in normal-tension glaucoma. Ophthalmology 2019;126:967-79.

25. Quaranta L, Riva I, Floriani I. Ginkgo biloba extract improves visual field damage in some patients affected by normal-tension glaucoma. Invest Ophthalmol Vis Sci 2014;55:2417. 